\title{
Third language vocabulary acquisition The influence of Serbian and Hungarian as native languages on the English language
}

Ivana Cvekić*

\begin{abstract}
This paper examines the influence of bilingualism on the use of vocabulary learning strategies during the acquisition of a third language. More precisely, it debates whether having a knowledge of two languages is beneficial for the awareness and frequency of strategy use. In this analysis, the use of learning strategies of pupils bilingual in Hungarian and Serbian language is compared to their monolingual peers of Serbian language while acquiring English as a third language. Since third language acquisition (TLA) is a relatively new and unexplored area, little research has been done on this specific topic. This particular study is situated in Serbia and used a 5-point Likert scale questionnaire as a way of collecting data consisting of two parts. The first part was based on three questionnaires on vocabulary strategies proposed by Gu and Johnson (1996), and Schmitt (1997), and on Oxford's (1990) Strategy Inventory for Language Learning. The second part consisted of pupils' suggestions and thoughts on learning strategies, together with their background information. Further discussion focuses on the use of bilinguals' vocabulary strategies and their frequency compared to monolinguals'.
\end{abstract}

Key words: bilingualism, learning strategies, vocabulary, third language acquisition

* Alpen-Adria-Universität Klagenfurt, Department of English; ivanacv@edu.aau.at 


\section{Introduction and background}

Vocabulary acquisition is one of the essential aspects of language proficiency. Having knowledge of only grammatical structures is not sufficient to contribute to a successful language acquisition. There should be a certain amount of vocabulary knowledge that can aid a foreign language competence. Following these lines, beginners are pressured to store many words in their memory and prepare them for instant use. Oxford and Scarcella (1994) suggest that vocabulary learning strategies help users of a foreign language (FL) reach a certain number of remembered words. Thus, the knowledge of various language strategies can potentially aid reaching a high FL proficiency.

The research on language strategies has reached its bloom in the last forty years. So far, various aspects of the field have been examined in more detail, with vocabulary strategies being one of the important components. For instance, according to the research in vocabulary strategies (Nation 1990), words which have a high frequency are important in vocabulary learning and teaching. So far, many studies in linguistics have focused on positive strategies and "good learner" strategies (Nation 1990, Oxford 1990, $\mathrm{Gu}$ and Johnson 1996, Thornbury 2002).

Vocabulary learning was of particular interest for the field of second language acquisition (SLA). The area of vocabulary acquisition was not given much importance around 1950s due to former dominating approaches, which emphasized the importance of grammar and phonology. Generative transformational linguistics (Chomsky 1957) is one of the theories labeling vocabulary as secondary to language acquisition. Somewhere around the 1970s, teaching perspectives started to change. Instead of a teacher-oriented approach, the focus was on learners' awareness and control of a language. Considering that pupils are becoming more active in the process of acquisition, learning strategies should be presented as tools for reaching a desired competence in a FL.

However, there are few studies in the area of third language acquisition (TLA) focusing on vocabulary learning strategies. Even though learning strategies in general have been researched in the last four decades, most of the research has been done in the area of SLA, not taking into consideration multilingualism as a growing world phenomenon. Bilingualism as a phenomenon implies that there are two linguistic systems which can influence TLA. Therefore, there may be a certain preference or pattern in strategy use. The study of Hammaberg (2001) has shown that the first language is usually used as a pragmatic and metalinguistic source, while the second language functions as a lexical storage. On the other hand Cenoz (2001) and Wei (2003) argue that there is a tendency to use a language which is typologically closer as a source of transfer on a third language. This paper is focused on Hungarian/Serbian bilingual pupils who are currently acquiring English as a foreign language in Grammar schools in Serbia. Their preference towards vocabulary strategy use was analyzed and compared with monolingual peers, contributing to a better understanding of bilingual approaches towards strategy selection. 


\section{Categorization of vocabulary strategies}

According to Schmitt (2002), second language users tend to employ activities which require less active manipulation of information in vocabulary acquisition, such as rote repetition and memorization. Cohen and Aphek (1981) argue that these "shallow" strategies may be more suitable for beginners, as they do not contain too much information. Similarly, more complex strategies are presented as more effective in the case of intermediate or advanced foreign language users. Even though some generalizations towards strategy preference can be made, O’Maley and Chamot (1990) suggest that any strategy is a useful one if FL users are accustomed to it. More precisely, if learners make a conscious effort and actively manage strategies in their acquisition process, the chances of those strategies having an impact on vocabulary learning are higher.

Research on language learning strategies counts numerous typologies. One of them is Oxford's (1990) division on memory, cognitive, compensation, metacognitive, affective and social strategies. Furthermore, Oxford designed a questionnaire based on her typology of strategies. Oxfrod's SILL (Strategy Inventory for Language Learning) questionnaire consists of fifty items, grouped according to the six divisions mentioned above. Moreover, the questionnaire is based on a five-point Likert scale, with the poles indicating how strongly someone agrees or disagrees with a statement.

The weakness of Oxford's typology is that some of the strategies can be labeled with more than one term. Cook and Mayer (1983) and Nation (1990) suggested a vocabulary categorization between the initial discovery of words and the remembering of them. Also, considering that the questionnaire was designed more than two decades ago, the usefulness of some strategies is outdated. For instance, the omnipresence of technology in today's society provides a potential of creating various other strategies, which may possibly replace some (e.g. the use of flashcards). Furthermore, it is crucial to point out that the study is focused on the pupils' self-report of vocabulary strategy use. Schramm and Chamot (2007) suggest that pupils' self-perception does not necessarily have to reflect reality. Moreover, pupils may understand strategies differently and can also forget some strategies they use.

On the other hand, Schmitt (2002) organized the taxonomy of vocabulary strategies, counting fifty-eight strategies, according to the Oxford (1990) system. More precisely, they are classified according to the strategies of initial discovery of a word's meaning (discovery) and strategies for remembering the meaning (consolidation). Furthermore, the strategies are also classified according to five groups, determination, social, memory, cognitive and metacognitive. Determination strategies are used when a person encounters a new word, but has no source of information. In this case, the person can guess from context, knowledge of a language, or from a L1 cognate. Social strategies refer to the interaction with other people in order to discover the meaning or to remember a word. Moreover, memory strategies involve a conscious effort of retrieving a word, which does not require a deeper understanding of the lexeme. According to Oxford (1990), cognitive 
strategies manipulate language material through reasoning, note-taking, and summarizing, while metacognitive strategies include an organization of a learning process, such as planning a studying process, and evaluating successfulness and effectiveness of strategies.

There are many variables that affect a person's preference for selecting a particular learning strategy. Some of the factors that potentially have an influence on the effectiveness of strategies include context of learning, target language, and learner characteristics. Aside from factors such as gender, age, and national origin, Rebecca Oxford (2011, 260) suggests that motivation is also strongly linked to strategy use. Moreover, a study done by Schmitt (1997) emphasizes the importance of culture towards strategy preference. In the study of O'Malley and Chamot (1990), Asian learners which were trained in strategy use tended to perform lower in vocabulary tasks compared to their untrained peers. On the other hand, strategy training had a positive effect on Hispanic learners in comparison to the control group. Therefore, a high number of potential variables only reaffirms the complexity of language acquisition. Therefore, understanding learning strategies can help FL users be aware of the process of acquisition, and can encourage them to be active, independent learners.

\section{Methodology and participants}

The current study used a forty-five minute questionnaire in order to collect information about pupils' approaches to vocabulary strategy use. Moreover, it was based on three questionnaires on vocabulary strategies proposed by $\mathrm{Gu}$ and Johnson (1996), Schmitt (1997), and Oxford's (1990) Strategy Inventory for Language Learning (SILL, version 7.0) Therefore, the focus was on the preference towards strategy use when encountering a new word (discovery), and remembering the already encountered one (consolidation). The questions regarding this categorization are presented in the form of a five-point Likert scale. However, there were several additional questions regarding pupils' personal information and their own suggestions regarding language strategies, in case some examples were omitted. Considering that the paper aims at contrasting the preference between bilinguals and monolinguals, bilingual pupils were presented with some additional questions, which relate to the Hungarian/Serbian bilingual situation in the north of Serbia. Table 1 gives a detailed overview of the questions taken from different tests. The fourth category of sources consists of originally created questions, which were deemed as important to the study. 


\begin{tabular}{lccccr}
\hline & Gu \& Johnson (1996) & Schmitt (1997) & Oxford (1990) & Original & Total \\
\hline \hline Monolinguals & 15 & 25 & 8 & 13 & 61 \\
Bilinguals & 16 & 26 & 10 & 15 & 67 \\
\hline Total & 31 & 51 & 18 & 28 & 128 \\
\hline
\end{tabular}

Table 1: Sources of questionnaire formation in the case of bilinguals and monolinguals

As already mentioned in the introduction, the study focuses on the bilingual phenomenon in Serbia. More precisely, the research was focused on the northern part of Serbia, which consists of many minorities, and Hungarians are by far the largest one. Also, apart from the Serbian language, Hungarian is also given certain legal and educational rights which vary locally. Moreover, three cities that were chosen as a location for the research are Bečej, Zrenjanin and Novi Sad. In each town there is a Grammar school that teaches in both the Hungarian and the Serbian language. In all three cities only pupils in their fourth year were tested. More importantly, in both Serbian and Hungarian sections of the schools, the English language is taught for twelve years as a first foreign language. According to the curriculum, pupils should have reached the B1 (intermediate) level in their senior year of high school. The number of participants in both the bilingual and monolingual group was 55, leading to the number of 110 pupils in total.

\section{Results and discussion}

Before comparing the differences in strategy use regarding vocabulary, an estimation of internal consistency was made, which resulted in $68 \%$ of variance being reliable. Following the analysis of variance reliability, the first comparison was made in regard to discovery and consolidation strategies. Table 2 indicates that in both cases, monolingual students tend to employ strategies more frequently. This can particularly be seen in the example of discovery strategies (Table 2) whereby the mean of frequency use among monolinguals was 3.47 , as opposed to 3.1 among bilinguals.

\begin{tabular}{lcc}
\hline & Discovery (1997) & Consolidation \\
\hline \hline Monolinguals & 3.47 & 2.70 \\
Bilinguals & 3.1 & 2.64 \\
\hline
\end{tabular}

Table 2: Difference in means of discovery and consolidation strategies between two groups 


\begin{tabular}{lcc}
\hline DISCOVERY & Monolinguals & Bilinguals \\
\hline \hline Determination & 3,42 & 3,04 \\
Social & 3,57 & 3,37 \\
\hline \multirow{2}{*}{ CONSOLIDATION } & Monolinguals & Bilinguals \\
\hline \hline Social & 2,87 & 2,67 \\
Memory & 2,65 & 2,61 \\
Cognitive & 3,44 & 3,23 \\
Metacognitive & 2,31 & 2,29 \\
\hline
\end{tabular}

Table 3: Comparison of means among subcategories

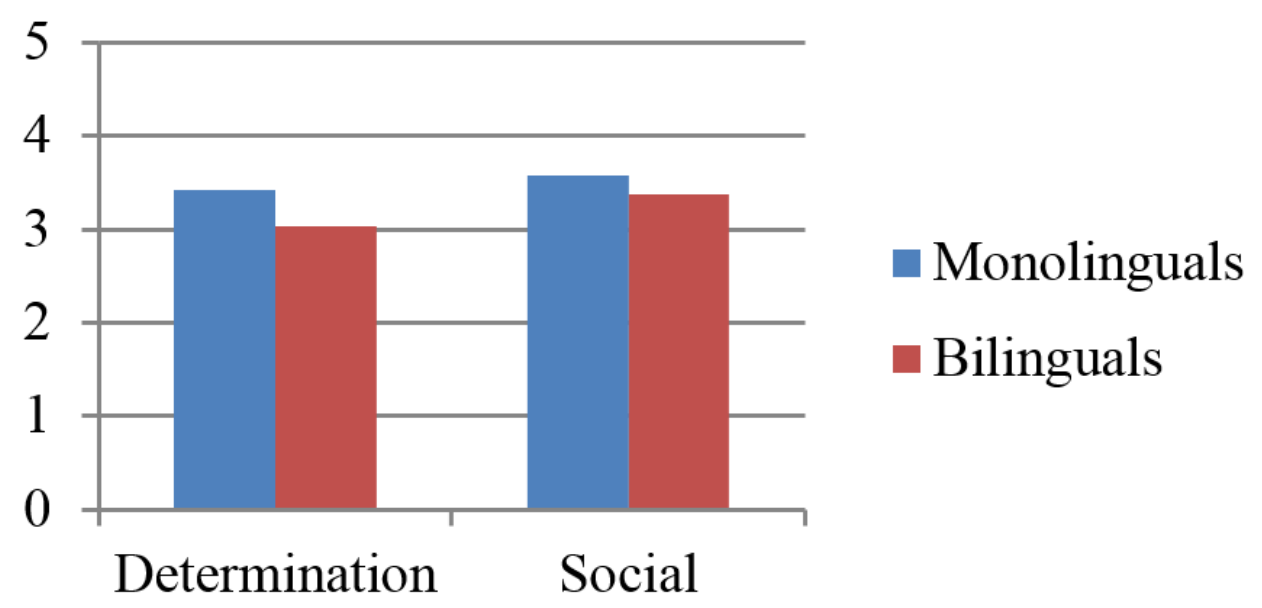

Figure 1: Comparison of means among determination and social strategies

As already stated, consolidation and discovery strategies can be further subdivided. In the case of discovery, the subcategories include determination and social strategies. On the other hand, consolidation strategies are divided into social, memory, cognitive and metacognitive. Table 3 covers the comparison of means among these subcategories.

Table 3 is also presented visually in two charts (Figure 1 and 2). What can be observed in Figure 1 is that monolinguals were by far more active in their use of both determination and social strategies. Furthermore, a major difference can be observed in the case of determination, whereby the mean among monolinguals was 3.42, compared to 3.04 among bilinguals.

Similarly, monolinguals were still more active in every subcategory of consolidation strategies, according to their self-report in the questionnaire. However, the difference in the mean was not that apparent. Therefore, Figure 2 shows that there is a slightly higher preference in the case of monolinguals. This difference is almost undetectable in regard to metacognitive and memory strategies. 


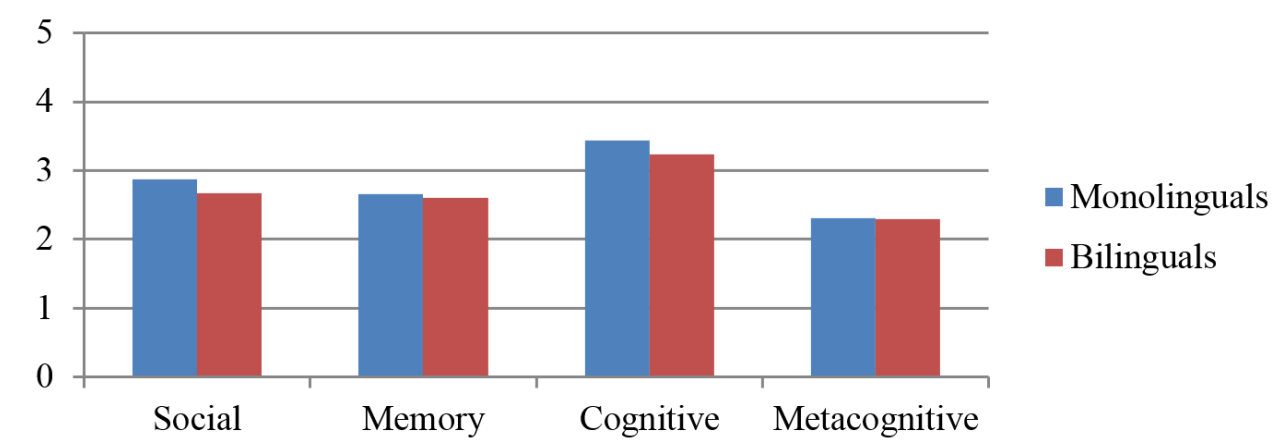

Figure 2: Comparison of means among social, memory, cognitive and metacognitive strategies

The following table (Table 4) provides examples of the five most frequent strategies from the questionnaire concerning discovery and consolidation strategies. All the examples are ordered from the highest mean to the lowest in both monolingual and bilingual cases. As could be seen in the consolidation section, metacognitive strategies are not preferred when remembering words. Even though various studies have emphasized a close connection between metacognitive strategies and bilingualism, this study shows no preference of bilingual learners in using metacognitive strategies for vocabulary acquisition in comparison to monolingual learners. What is more, in the case of both groups, it is the least preferred approach.

Apart from the division between discovery and consolidation strategies, there were also some additional questions. These questions covered the topics of dictionary use, source of vocabulary acquisition, anxiety, and motivation. Throughout the questionnaire, a Likert scale was used to calculate the results, and the means of the strategies mentioned was again contrasted between bilinguals and monolinguals. In the case of dictionary use (Table 5), it was shown that pupils from both groups mostly rely on its use for the purpose of discovering meaning. The strategies for using a word in a sentence and for a word's pronunciation are less frequent. However, bilinguals have a slightly higher preference for using dictionaries regarding word meaning and word use in a sentence.

Furthermore, other additional questions in the questionnaire refer to the most frequent source of English vocabulary. Some of the sources of word input, which were included in the questionnaire, were learning words during class, from books, video material and songs. Table 6 displays that visual input is one of the most frequent sources. However, audio input is another important source for both monolinguals and bilinguals. In this case, monolinguals have a higher tendency to use almost every source. This is apparent in the case of learning new words from listening to songs in English, with the mean among monolinguals being 4.36 compared to 3.8 for bilinguals. In the case of reading books, bilinguals (3.49) had only a slightly higher preference than the monolinguals (3.38). 
Monolinguals

1. I try to guess from the context. (D)

2. I analyze the sentence in order to guess the meaning. (D)

3. I rely on my experience and common sense. (D)

4. I prefer when the teacher gives an example in a sentence. ( $\mathrm{S}$ )

5. I prefer when the teacher paraphrases or gives a synonym. (S)

Bilinguals

I usually use an English-Hungarian dictionary when I see a new word. (D)

I prefer when the teacher gives an example in a sentence. $(\mathrm{S})$

D-Determination

S-Social

I use new words in speech and writing. (C)

2. I repeat the words that I've learned. (C)

3. I use new words in a context in order to remember. (M)

M-Memory

S-Social

C-Cognitive

MC-Metacognitive
4. I talk to someone who can speak English. (S)

5. I remember words by phrases. (M)
I use other means of discovery if I cannot find out the meaning right away. (D)

I prefer when the teacher translates a word in a native language. (S)

$\mathrm{I}$ rely on my experience and common sense. (D)

I use new words in speech and writing. (C) I imagine how the word is written. (M)

I repeat the words that I've learned. (C)

I link the new word with my experience. (M)

I analyze pronunciation of a new word. $(\mathrm{M})$

Table 4: The most frequent discovery and consolidation strategies in the case of monolinguals and bilinguals

Pupils

out the pronounciation.

\begin{tabular}{llrrr}
\hline \hline \multirow{2}{*}{ Monolinguals } & Mean & 2,5636 & 3,6909 & 2,6182 \\
& N & 55 & 55 & 55 \\
& Std. Deviation & 1,21356 & 1,08649 & 1,22461 \\
& Sum & 141,00 & 203,00 & 144,00 \\
\hline \multirow{2}{*}{ Bilinguals } & Mean & 2,5091 & 3,7273 & 2,8000 \\
& N & 55 & 55 & 55 \\
& Std. Deviation & 1,16861 & 1,09637 & 1,20800 \\
& Sum & 138,00 & 205,00 & 154,00 \\
\hline \multirow{2}{*}{ Total } & Mean & 2,5364 & 3,7091 & 2,7091 \\
& N & 110 & 110 & 110 \\
& Std. Deviation & 1,18614 & 1,08658 & 1,21418 \\
& Sum & 279,00 & 408,00 & 298,00 \\
\hline
\end{tabular}

Table 5: Dictionary use 


\begin{tabular}{llrrrr} 
Pupils & & $\begin{array}{r}\text { I learn new words } \\
\text { in the class. }\end{array}$ & $\begin{array}{r}\text { I learn new words } \\
\text { while reading } \\
\text { books in English. }\end{array}$ & $\begin{array}{r}\text { I learn new words } \\
\text { while watching } \\
\text { TV, movies, } \\
\text { series in English. }\end{array}$ & $\begin{array}{r}\text { I learn new words } \\
\text { while listening to } \\
\text { songs in English. }\end{array}$ \\
\hline \hline Monolinguals & Mean & 3,3091 & 3,3818 & 4,5455 & 4,3636 \\
& N & 55 & 55 & 55 & 55 \\
& Std. Deviation & 1,27472 & 1,35388 &, 74082 &, 67669 \\
& Sum & 182,00 & 186,00 & 250,00 & 240,00 \\
\hline Bilinguals & Mean & 3,2364 & 3,4909 & 4,2364 & 3,8000 \\
& N & 55 & 55 & 55 & 55 \\
& Std. Deviation & 1,08804 & 1,05185 &, 74445 & 1,02560 \\
& Sum & 278,00 & 192,00 & 233,00 & 209,00 \\
\hline Total & Mean & 3,2727 & 3,4364 & 4,3909 & 4,0818 \\
& N & 110 & 110 & 110 & 110 \\
& Std. Deviation & 1,18018 & 1,20798 &, 75535 &, 91000 \\
& Sum & 360,00 & 378,00 & 483,00 & 449,00 \\
\hline
\end{tabular}

Table 6: Sources of word input

Considering that vocabulary acquisition is a complex process, it is influenced by various variables. Affective factors are another important part of the acquisition. Yet, the study of all personality factors would require a much more extensive analysis. For this questionnaire, affective factors were limited only to anxiety and motivation. Even though both of the variables require a detailed research, this paper restricts itself to the application of a more general approach. a more general approach. According to the pupils' self-report, it seems that bilinguals were less motivated for learning new words in English (Table 7). Not only was their motivation lower, but they also had a higher level of anxiety during the process (Table 8 ). In other words, bilinguals have a harder time remembering words than their monolingual peers, while the case is quite the opposite for monolinguals who demonstrated a higher motivation and a lower level of anxiety.

I am motivated to learn new words in English.

\begin{tabular}{lrrrr}
\hline Pupils & Mean & N & Std. Deviation & Sum \\
\hline \hline Monolinguals & 3,7636 & 55 & 1,17005 & 207,00 \\
Bilinguals & 3,50911 & 55 & 1,16861 & 193,00 \\
\hline Total & 3,6364 & 110 & 1,17096 & 400,00 \\
\hline
\end{tabular}

Table 7: Comparison of motivation means 
I find it difficult to remember new words in English.

\begin{tabular}{lrrrr}
\hline Pupils & Mean & N & Std. Deviation & Sum \\
\hline \hline Monolinguals & 2,0364 & 55 & 1,07089 & 112,00 \\
Bilinguals & 2,2000 & 55 &, 98883 & 121,00 \\
\hline Total & 2,1182 & 110 & 1,02922 & 233,00 \\
\hline
\end{tabular}

Table 8: Comparison of anxiety means

Another interesting aspect is the choice of the native language for lexical storage and grammar for bilinguals. In other words, the question referred to the first word translation that pupils think of. The following question inquired about the background grammar they rely on more, when learning the grammar of English. Figure 3 shows that bilinguals tend to rely more on the Hungarian language for both translation (3.49) and grammar (2.8).

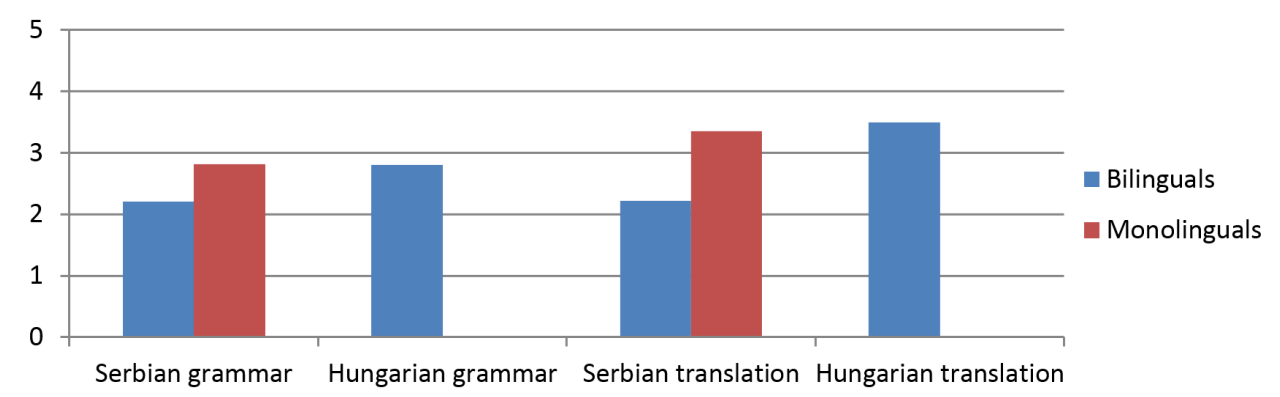

Figure 3: Comparison of grammar and translation means

In addition, four other questions were given regarding conscious organizational strategies, i.e. whether the pupils' focus in vocabulary learning was on the most frequently used words, on vocabulary used in a test, or on personal interest. Both groups of pupils are more eager to learn words that interest them, when compared to other factors. Moreover, the interest in vocabulary is followed by the frequency of words as the second important factor in the vocabulary acquisition process. Yet, in terms of focusing on the words for the test, bilinguals had a higher preference (2.76) than monolinguals (2.38). This means that aside from personal motivation, they were also highly motivated in learning English vocabulary as an instrument for meeting class requirements. 


\begin{tabular}{llrrrr} 
Pupils & & $\begin{array}{r}\text { I focus only on } \\
\text { words for the } \\
\text { test. }\end{array}$ & $\begin{array}{r}\text { I know which } \\
\text { words are } \\
\text { important for } \\
\text { me. }\end{array}$ & $\begin{array}{r}\text { I look up the } \\
\text { maning only of } \\
\text { those words } \\
\text { which interest } \\
\text { me. }\end{array}$ & $\begin{array}{r}\text { I only learn the } \\
\text { words which are } \\
\text { used most } \\
\text { frequently. }\end{array}$ \\
\hline \hline Monolinguals & Mean & 2,3818 & 3,6000 & 4,0727 & 3,6182 \\
& N & 55 & 55 & 55 & 55 \\
& Std. Deviation & 1,28367 & 1,14827 &, 97856 & 1,13024 \\
& Sum & 131,00 & 198,00 & 224,00 & 199,00 \\
\hline Bilinguals & Mean & 2,7636 & 3,2727 & 3,7091 & 3,5636 \\
& N & 55 & 55 & 55 & 55 \\
& Std. Deviation & 1,29047 & 1,16197 & 1,21217 & 1,08463 \\
& Sum & 152,00 & 180,00 & 204,00 & 196,00 \\
\hline Total & Mean & 2,5727 & 3,4364 & 3,8909 & 3,5909 \\
& N & 110 & 110 & 110 & 110 \\
& Std. Deviation & 1,29543 & 1,16152 & 1,11162 & 1,10292 \\
& Sum & 283,00 & 378,00 & 428,00 & 395,00 \\
\hline
\end{tabular}

Table 9: Additional questions compared

In the last section of the questionnaire, pupils were given the option of writing their own suggestions of strategies, which were not mentioned in the taxonomy. The questions were mainly aimed at discovery and consolidation strategies. Table 10 shows that both groups use very creative approaches. An interesting point is that even though pupils form Serbian classes are in theory monolingual, they still use other languages for the acquisition of a vocabulary. The examples include using German language, borrowing, and code-mixing. Other examples include modern technology (videogames, cell phones) and the accessibility of internet. Some of the pupils even have the opportunity of talking to English native speakers. Even though it is not mentioned, it may be possible that this communication is also achieved via today's technology.

\begin{tabular}{lll}
\hline & Bilinguals & Monolinguals \\
\hline \hline Discovery & Videogames & Internet (google) \\
& & Billboards \\
& & Text messages \\
& & Using German \\
\hline Consolidation & Talking to native speakers & Movies with English subtitles \\
& Drawing & Using new words in essays \\
& & Borrowing \\
& & Code-mixing \\
\hline
\end{tabular}

Table 10: Pupils' suggestions on vocabulary strategies 


\section{Conclusion}

The evidence shows that monolingual pupils are more interested in a higher number of strategies. Only in the case of metacognitive strategies, both groups had the same level of preference. Moreover, for both monolinguals and bilinguals, determination strategies were the most prominent ones from the discovery category. On the other hand, cognitive strategies had a high frequency in the consolidation group. Furthermore, bilingual dictionaries are mostly used for discovering the meaning of a word. There was also a high use of visual and auditory materials for vocabulary input. However, bilinguals tend to use books slightly more for the acquisition of words. Furthermore, as affective factors influence the process of acquisition, it is important to note that in the case of bilinguals motivation was slightly lower when compared to monolinguals. This was quite the opposite when regarding anxiety, as bilinguals find it harder to learn new words. Yet, all the groups mostly focus on learning words that interest them. Only in the case of focusing on words for the test, bilinguals showed a higher interest. Once again, self-report questionnaires should always be interpreted in a way that takes into account the limiting factor of subjectivity and the subjective reality of participants.

Moreover, when discussing CLI, it has been shown that bilinguals rely on Hungarian in both word translation and grammar comprehension. However, when pupils were asked to share their personal strategies, many of them mentioned the use of other languages than their native ones. This only shows that today's world is not being guided anymore according to monolingual norms. Even though it may seem easy to label someone as a monolingual, all the pupils are in constant contact with various languages on a daily basis. Furthermore, pupils also mentioned the intensive use of modern technology. This only shows that questionnaires should be updated according to today's trends in order to take into consideration modern technologies and the increasingly multilingual realities of contemporary societies.

\section{References}

Chomsky, Noam. 1957. Syntactic Structures. The Hague: Mouton.

Cohen, Andrew D., and Edna Aphek. 1981. "Easifying Second Language Learning." Studies in Second Language Acquisition 3 (2): 221-236.

Cook, Linda K., and Richard E. Mayer. 1983. "Reading Strategies Training for Meaningful Learning from Prose.” In Cognitive Strategy Research: Educational Applications, edited by Michael Pressley and Joel R. Levin. 87-131. New York: Springer.

$\mathrm{Gu}$, Yongqi, and Robert Keith Johnson. 1996. "Vocabulary Learning Strategies and Language Learning Outcomes.” Language Learning 46 (4): 643-679.

Hammarberg, Björn. 2001. "Roles of L1 and L2 in L3 production and acquisition." In Crosslinguistic influence in third language acquisition: Psycholinguistic perspectives, edited by J. Cenoz, B. Hufeisen, and U. Jessner, 21-41. Clevedon: Multilingual Matters. 
Nation, I. S. P. 1990. Teaching and Learning Vocabulary. New York: Newbury House Publishers. O’Malley, J. Michael, and Anna Uhl. Chamot. 1990. Learning Strategies in Second Language Acquisition. Cambridge: Cambridge University Press.

Oxford, Rebecca L., and Robin C. Scarcella. 1994. "Second Language Vocabulary Learning among Adults: State of the Art in Vocabulary Instruction.” System 22 (2): 231-243.

Oxford, Rebecca L. 1990. Language Learning Strategies: What Every Teacher Should Know. Boston: Heinle \& Heinle.

Oxford, Rebecca L. 2011. Teaching and Researching Language Learning Strategies. Harlow: Longman.

Schmitt, Norbert. 1997. "Vocabulary Learning Strategies." In Vocabulary Description Acquisition and Pedagogy, edited by Schmitt and McCarthy. Cambridge: Cambridge University Press.

Schmitt, Norbert. 2000. Vocabulary in Language Teaching. Cambridge: Cambridge University Press.

Wei, L. 2003. "Activation of lemmas in the multilingual mental lexicon and transfer in third language acquisition.” Bulletin VALS-ASLA 78, 1-11. 